\title{
Serbian Citation Index: The sustainability of a business model based on partnership between a non-profit web publisher and journal owners
}

Milica Ševkušić, Biljana Kosanović and Pero Šipka

\section{Introduction}

1 The Open Access (OA) and Open Science (OS) movements have led to global changes in scholarly communication, including publishing. Over the past years, we have witnessed the rise of the Directory of Open Access Journals (DOAJ) as a 'white list' of OA journals (Marchitelli et al.), flipping journals to full open access (Solomon et al.), initiatives to move away from traditional bibliometrics (Marx and Bornmann), development of data publishing workflows (Austin et al.) and open peer review (Ross- Hellauer), Plan S ('Principles and Implementation'), as the Global North's path towards unrestricted online access to research literature, and the rise of non-profit $\mathrm{OA}$ infrastructures for scholarly communication in the Global South (Aguado-López and Becerril-Garcia).

2 In this eventful landscape, attention is increasingly focused on the diversity of business models and there is a growing awareness that fee-based OA publishing is not the only model, that the percentage of OA journals that do not charge publication fees is significant and that there are parts of the world where no-fee $\mathrm{OA}$ is the dominant model (Crawford).

3 Serbia is one of the countries where no-fee OA is the 'standard' model in scholarly journal publishing. The Serbian Citation Index (SCIndeks) is the largest OA publishing platform in Serbia. It is developed by the Centre for Evaluation in Education and Science (CEON/CEES) and it currently hosts full-text articles from 156 active journals 
and full text and/or abstracts from 107 journals which either ceased publishing or their coverage in SCIndeks has been discontinued. Similarly to the Croatian national journal portal (Hrčak) and international initiatives such as SciELO, it initially relied on public funding. The business model was later changed due to the cessation of public funding ('SCIndeks Changed Its Shape, Scope, and Funding Model - CEON/CEES Announcement'). This study addresses the key elements of the new business model and the technical improvements focused on delivering functional and competitive services and their role in achieving sustainability.

Scholarly publishing in Serbia is marked by the persistence of print culture, reliance on public funding, orientation towards a local readership (especially in social sciences and humanities), and a general acceptance of $\mathrm{OA}$ as an idea but failing to meet technical quality. Journals are usually owned and published by institutions and learned societies on a non-profit basis (Ševkušić et al. 11-14, 18). Attempts to sell subscriptions to online publications have been scarce, while partnering with international publishers has never become a widespread practice, either because their services are not affordable or because local publishers are reluctant to lose editorial control. It is estimated that there are more than 500 active scholarly journals in Serbia. Apart from SCIndeks, there are several smaller OA journal clusters in Serbia, ${ }^{1}$ marked by limited functionality and poor interoperability, as well as a large number of individual journal websites of varying quality. Many journals do not have independent websites but present their content using the websites of their owners (publishers) and even social networking sites.

SCIndeks was established in 2004 (Šipka, 'The Serbian Citation Index'). It draws on earlier OA projects of the CEON/CEES and its research related to citation indexes and bibliographic databases and especially on SocioFakt (Kosanović and Šipka), which contained articles from local journals in social sciences. Unlike SocioFakt, SCIndeks covered all research areas, integrating a citation bibliographic database and a full-text archive. Initially, SCindeks was the source of information for the Journal Bibliometric Report (JBR) (Šipka and Kosanović; Popovic et al.), an official tool used in the evaluation of local journals. ${ }^{2}$ Both SCIndeks and JBR were funded publicly, through open calls by the ministry responsible for science. In 2011, the platform was enriched with a journal management system (through the integration of the Open Journal Systems - OJS) and screening for plagiarism (iThenticate). These advanced services were offered to publishers for a fee. Occasional grants were an additional source of funding.

6 In 2015, public funding suddenly ceased due to political changes in the state administration, leading to changes in SCIndeks's business model. Until that moment, SCIndeks indexed 475 journals. More than half of these (284) were given at abstractlevel and 191 in full text, while only 37 used the advanced publishing features.

7 The new business model is based on a partnership between CEON/CEES, as the owner of a journal publishing platform, and journals willing to collaborate with this organization within a specific, innovative framework. CEON/CEES is responsible for web publishing, quality control, evaluation, and dissemination, for which services it collects an annual subscription fee from journals. The fee is intended to cover all expenses, from platform maintenance and development to charges for services provided by third parties, such as platform hosting, DOI assignment, or plagiarism screening. Editorial boards participate as partners in decision-making regarding further platform development, which is aligned with their dominant needs and implementation costs of new functionalities. Various channels and instruments (regular technical support, webinars, 
online interviewing, customer needs surveys), are regularly used for the purpose. Final decisions are made in a non-formal process. Mutual relations and obligations between CEON/CEES and journals are formalized in separate contract agreements. The platform operates on a non-profit basis. The access to the published content is unrestricted. All journals hosted on the platform are $\mathrm{OA}$, and the vast majority of them do not charge authors for publishing. ${ }^{3}$

8 In the context of $\mathrm{OA}$ publishing, this business model may be roughly classified as Platinum Open Access, Diamond Open Access, or the no-fee model, sometimes also called "publisher-pays" model (Solomon et al.), since all publishing costs are covered by the journal publisher alone. However, in case of SCIndeks, there is a major difference, because a substantial share of expenses is covered by CEON/CEES as the platform owner. As a non-profit organization, CEON/CEES performs its activities for free, charging journal owners for production costs only. This makes SCIndeks's model innovative, if not unique, in journal publishing, and its sustainability an intriguing issue, worth of critical analysis and assessment.

\section{Methodology}

9 The analysis relies on a comparison between the old public-pays model and the new business model behind SCIndeks, as well as on the comparison between SCIndeks and international journal publishing platforms of similar role and status (OA). Comparisons were made mostly in terms of the qualitative features, reflecting sustainability as our primary interest. The quantitative data were used whenever available and comparable. The comparisons made may be classified into the following groups of sustainability indicators:

- Platform growth (increased number of indexed journals, increased demand for more complex services, in general and in particular research areas);

- Potential for keeping up with global trends in scholarly publishing (providing new services and implementing new standards);

- Financial performance (budget size and stability in relation to real expenses); and

- Comparability with similar national/regional platforms (in terms of usefulness and functionality).

In the analysis of two SCIndeks models, we employed quantitative data regularly collected by CEON/CEES as part of internal monitoring and self-assessment procedures. A comparison between SCIndeks and similar national/regional publishing platforms was discussed based on their features as described on their websites. and literature data

\section{Platform growth}

11 The cessation of public funding in 2015 was unexpected both for CEON/CEES and journal publishers. It took months before the ministry responsible for science provided official information to publishers, due to which the sudden transition to a new business model was received with confusion. ${ }^{4}$ At the beginning of this process, the coverage was limited to several dozen journals subscribing to one of the service packages. Over time, the number of journals returning to SCIndeks gradually increased. In early 2020, 
SCIndeks covers 263 journal titles (156 regularly published; see Table 1). Out of these 156 journals, 110 were indexed in SCIndeks before 2015, whereas the remaining 46 are new.

The shift from a primarily bibliographic database and evaluation tool to a fully $\mathrm{OA}$ platform is reflected in the growing percentage of the OA full-text content (Table 1). Although the share of full-text articles was growing steadily before 2015, this growth has accelerated after the change of the business model. Beginning with 2020, SCIndeks will only host journals providing full-text content.

Table 1. The number of journals per service package and the growth of the full-text content after 2015

\begin{tabular}{|c|c|c|c|c|c|c|c|}
\hline \multirow{2}{*}{ Year } & \multicolumn{5}{|c|}{ Journals } & \multicolumn{2}{|l|}{ Articles } \\
\hline & Basic & Extended & Advanced & Professional & Total & Total & Full-text \\
\hline 2015 & 28 & 11 & 62 & 36 & 137 & 5841 & $4329(74.11 \%)$ \\
\hline 2016 & 25 & 11 & 63 & 48 & 147 & 5661 & 4355 (76.93\%) \\
\hline 2017 & 19 & 9 & 69 & 53 & 150 & 4970 & $4386(88.25 \%)$ \\
\hline 2018 & 10 & 7 & 72 & 66 & 155 & 4922 & $4542(92.28 \%)$ \\
\hline 2019 & 3 & 4 & 74 & 78 & 159 & 3981 & 3805 (95.58\%) \\
\hline 2020 & 0 & 0 & 70 & 86 & 156 & pending & pending \\
\hline
\end{tabular}

13 The rise in the percentage of the full texts is related to publishers' growing preference for more complex service packages (Table 1). Until 2020, there were four packages: Basic (article-level indexing), Extended (basic full-text indexing), Advanced (full-text indexing, DOI assignment, integration of ORCIDs, processing and normalization of cited references, OAI-PMH) and Professional (Advanced package enriched with the online publishing system - SCIndeks Asistent ${ }^{5}$ ). In 2020, the Basic and the Extended packages were discontinued, as publishers' interest have shifted towards more complex services. The packages provide not only different levels of indexing depth but also different levels of quality control over editorial procedures and the published content. ${ }^{6}$ The fact that an increasing number of publishers choose the most complex (and most expensive) package indicates a growing need for more detailed indexing and more efficient dissemination, as well as for a greater control over the publishing process.

Until 2015, for a significant number of journals, SCIndeks was the only online venue where they could present their content in a structured and interoperable way free of charge. Since 2015, some journals ventured into establishing independent websites, encouraged by the fact that free and open-source software (OJS) was available, whereas a few others partnered with international publishers (mostly De Gruyter). These paths turned out to be more difficult and/or expensive than expected, and some of these journals eventually subscribed to SCIndeks services, realizing their cost-effectiveness. 
The Basic and Extended packages were offered with the idea of facilitating a transition from bibliographic indexing to a publishing process where all steps involve quality control. They were offered as a temporary solution and were discontinued as soon as the number of subscribing journals became insignificant. Further efforts will be directed towards encouraging journals to make a shift from the Advanced to the Professional package.

16 The data also reveal that the growth under the new business model is skewed towards social sciences. The transition to the new business model resulted in a changed structure of the full-text content (Table 2). As expected, the representation of research areas was more balanced when SCIndeks was a publicly funded project.

Table 2. The number and percentage of full-text articles in SCIndeks per area of research before and after the transition to the new business model

\begin{tabular}{|l|l|l|l|l|l|l|l|l|l|l|l|l|}
\hline & \multicolumn{2}{|l|}{ Science } & \multicolumn{2}{l|}{$\begin{array}{l}\text { Medical } \\
\text { sciences }\end{array}$} & \multicolumn{2}{l|}{ Agriculture } & \multicolumn{2}{l|}{ Engineering } & \multicolumn{2}{l|}{$\begin{array}{l}\text { Social } \\
\text { sciences }\end{array}$} & \multicolumn{2}{l|}{ Humanities } \\
\hline $\begin{array}{l}\text { Before } \\
2015\end{array}$ & 7193 & $12.41 \%$ & 11183 & $19.29 \%$ & 6329 & $10.92 \%$ & 9844 & $16.98 \%$ & 10716 & $18.48 \%$ & 12710 & $21.92 \%$ \\
\hline $\begin{array}{l}2015- \\
2019\end{array}$ & 274 & $\begin{array}{l}1.28 \% \\
\%\end{array}$ & 5526 & $\begin{array}{l}25.80 \% \\
\%\end{array}$ & 1418 & $\begin{array}{l}6.62 \% \\
\%\end{array}$ & 3643 & $\begin{array}{l}17.01 \% \\
\%\end{array}$ & 8668 & $40.47 \%$ & 1888 & $\begin{array}{l}8.82 \% \\
\%\end{array}$ \\
\hline
\end{tabular}

After 2015, the number of journals in social sciences in SCIndeks has been increasing: 25 new journals (not indexed under the old business model) have joined SCIndeks. The percentage of full-text articles in this area is currently the highest (around $40 \%$ of the annual production of the hosted journals). This suggests that journal publishers in social sciences and to some extent in medicine recognize SCIndeks as an efficient publishing gateway and the first step in achieving international prestige. Journals from hard sciences are generally looking for more direct access to the international scene, while those from humanities estimate their chances as small anyway.

\section{Potential for keeping up with global trends in scholarly publishing}

18 The quality of services did not decrease with the cessation of public funding. One of the reasons for this was that both the infrastructure and expertise necessary to maintain SCIndeks and the related services had been developed and owned by CEON/CEES. None of the key skills, including metadata creation and enrichment, database organization, a detailed knowledge of traditional bibliometric methodology and research focused on developing new bibliometric and quality indicators, was outsourced. This has remained so in the new business model.

After 2015, great attention has been paid to the adoption of skills that are in line with the global developments in $\mathrm{OA}$ publishing and innovations in this area (e.g. interoperability, PIDs, open citations, journal policies, licensing, (alt)metrics, etc.). Another area of special CEON/CEES's interest is the delivery of user support and training, which is facilitated by online tools. A lot has been invested in the development 
of IT skills. CEON/CEES staff members are also encouraged to get involved in research. Nevertheless, some aspects of the IT segment still require outsourcing and this is a major development challenge because it is very difficult to find affordable IT staff interested in non-profit academic publishing.

A new development strategy involves constant workflow improvements and additional services. The services are based on an analysis of local publishers' needs and their feedback, but also on the analysis of global trends. SCIndeks seeks to increase the quality and visibility of local journals and facilitate their inclusion into international infrastructures by downscaling and adapting global models and good practice to a national level. The advanced services introduced after the transition to the new business model, include:

1. ORCID integration (2016-2017);

2. normalization of funder information (2016-2017) and references/citations;

3. machine-readable Creative Commons licenses (2016-2017);

4. depositing enhanced metadata in CrossRef (ORCID, FundRef IDs and Funding Award Numbers, license information, multilingual titles, abstracts, and references as open citations in accordance with the Initiative for Open Citations - I4OC; 2017);

5. Policy and Licensing Support Service enabling journals to define their editorial policies relying on a standardized template compliant with the requirements set by DOAJ (20162017) ('A New SCIndeks Functionality: Policy and Licensing Support Service');

6. improved journal management enabling the identification of retracted articles among the references of submitted manuscripts, as well as papers from disputable journals (Mind the Trap, 2017);

7. evaluation of peer reviews and reviewers by manuscript authors, not only by editorial boards, as in the past (RevRev, 2017-2018);

8. rewards for the best reviewers (2019), enabled by RevRev ('Award and Acknowledgments for the Reviewers of SCIndeks Assistant Journals Established');

9. technical support in applying for indexing in DOAJ (2016-2017);

10. articles metadata delivery to DOAJ, OpenAIRE and BASE (2016-2017) (Šipka, Supporting SCIndeks Improvements through Alternative Funding Mechanism: CEON/CEES Project Execution Final Report);

11. technical support in applying for indexing in the Web of Science and Scopus (2019).

21 Great attention is paid to the quality of metadata and content dissemination. SCIndeks has the OAI-PMH interface, and article metadata are delivered to OpenAIRE (https:// explore.openaire.eu/) and BASE (https://www.base-search.net/). At the moment, the SCIndeks development team delivers metadata to the Directory of Open Access Journals (DOAJ) on behalf of 69 journals.

Although it is not used in the official evaluation of journals conducted by the ministry responsible for science, JBR is still published once a year as an online application independent of SCIndeks (http://bic.ceon.rs). After 2015, the methodology, ${ }^{7}$ which basically relies on the traditional bibliometric analysis used in the Journal Citation Reports, but heavily enriched with additional indicators adjusted to the local context, has shifted away from traditional bibliometrics to include a number of qualitative indicators (transparent journal policies, licenses, indexing in DOAJ, screening for plagiarism, etc.). The access to JBR is reserved for the partners (indexed journals owners and contracted universities), as well as publishers of international citation 
indexes and, upon request, field experts involved in evaluation research. A brief outline of evaluation results for individual journals is publicly available on their pages in SCIndeks. The primary function of JBR in the new business model is to provide information and guidance to publishers and editors towards improving the quality of their journals.

Since 2017, SCIndeks displays content usage indicators (visits and downloads) for all indexed journals. In 2020, Altmetric and Dimensions APIs were integrated into the platform. Altmetric Attention Scores and Dimensions citations are displayed at article level.

Further steps will be focused on ensuring Plan S compliance for the hosted journals. In this respect, the availability of full text in "a machine-readable community standard format such as JATS XML" remains a major challenge. Solutions and workflows for most other requirements (open citations, COPE-compliant policies, PIDs, OpenAIRE compliance, linking articles with the corresponding research data, etc.) have already been developed but need to be extended to the full range of the hosted journals.

\section{Financial performance}

Before 2015, the public funding by the Ministry of Science ensured a seemingly good but in fact uncomfortable position for CEON/CEES in financial terms. The annual budget for the national citation index and JBR, covering more than 500 journals, was permanently tight, varying within the range of $60.000-90.000 €$, which was hardly sufficient for regular maintenance, let alone the improvement of the system requiring permanent innovations imposed by the fast-paced changes in academic publishing. The necessary improvements, such as DOI assignment for articles or the localization and adaptation of OJS, were financially supported by journal publishers interested in adopting new standards and practices. The budgeting was additionally supported by the resources (database hosting and working space for administrators) provided by the National Library of Serbia, CEON/CEES's partner according to the decision of the Ministry.

After the cessation of public funding in 2014, CEON/CEES was forced to announce a call inviting journals to participate in the indexing costs. The call was accompanied with the elaboration of the organizational and financial framework for what would soon thereafter become the new SCIndeks business model. The transition to a new participatory-based financing model was unavoidable, as it would have been impossible for a small non-profit organization ${ }^{8}$ to keep on maintaining and developing a national infrastructure without adequate funding provided for this purpose.

The journals' response rate to the call was unexpectedly high, keeping in mind that the new business model could only have been understood as a dubious plan for an almost adventurous joint venture. Still, the initial number of journal owners and editorial boards ready to enter a partnership with CEON/CEES was insufficient to cover all operational costs. In subsequent years, with the constant improvement of services, the situation gradually, though steadily improved. The number of journals subscribing to the most expensive package (Professional) more than doubled in the five-year period, as evident from Table 3. Thanks to this and other sources of income (e.g. special service contracts with some universities on using SCIndeks data in the evaluation of faculties and departments), SCIndeks's budget finally, in 2020, exceeded the amount provided by 
the Ministry in the past, ensuring conditions for investing in the developments outlined in the previous section.

The financial sustainability is further supported by the structure of the partnering publishers, the majority of whom rely either on public funding (public institutions and research organizations) or membership fees (learned societies). Journals published by public institutions and public research organizations account for more than $60 \%$, whereas journals published by learned societies account for nearly $30 \%$ of all SCIndeks journals. Furthermore, nearly $40 \%$ of the hosted journals receive funding through publishing support programmes of the Ministry of Education, Science and Technological Development and the Ministry of Defence. Although limited, their funding streams are stable, enabling them to cover the cost of service packages and function without charging any fees from the authors.

\section{Comparability with similar national/regional platforms}

In the local context, SCIndeks remains a unique and solitary project focused on increasing the international visibility and reputation of local scholarly journals by providing a digital infrastructure, while guiding journals' policies and supervising their practices. At the same time, in an international landscape, it finds parallels in a number of non-profit, multidisciplinary, national and regional indexing and publishing $\mathrm{OA}$ platforms, which require journals to meet some level of editorial quality, while leaving the ownership and editorial control in the hands of publishers. For the purpose of this study we will briefly refer to some shared features between SCIndeks and SciELO (Latin America, started in 1998), AJOL (Africa, started in 1998; Rosenberg), Redalyc (Latin America, started in 2003) and Hrčak (Croatia, started in 2006; Stojanovski et al.), The mentioned platforms are chosen as representative of one or more concepts and features relevant for SCIndeks. SciELO combines a full-text database and a citation index. AJOL, as the most developed platform established within the Journals Online (JOLs) project," shows a slower transition towards full OA and an approach to the implementation of OJS that is rather different from SCIndeks's. Striving to maintain the non-commercial character of scholarly publishing in Latin America, Redalyc is changing its strategy and business model (Becerril-García and Aguado-López). Finally, Hrčak is a national platform established in a country with a similar structure of scholarly publishers, research community and publishing tradition.

All these platforms have appeared in response to the "mainstream" scholarly publishing, dominated by multinational commercial publishers, as an attempt to support local or regional initiatives by providing a shared infrastructure, dissemination (mainly through OAI-PMH (Stojanovski et al.; Aguado López and Becerril-Garcia; Alperin)) and technical support. They were also intended to mitigate the underrepresentation of local research, especially in local languages, in international bibliographic databases (Cetto and Alonso-Gamboa; Van Leeuwen et al.; Meneghini and Packer; Packer 21-24) and their inability to capture citations and measure its true impact (Packer 27-30). Just like SciELO (Packer) and Hrčak (Stojanovski et al.), SCIndeks (Šipka, 'Bibliometric Quality of Serbian Journals 2002-2011') has played an important role in preparing local journals to qualify for indexing in international citation indexes. While SCiELO and SCIndeks have used bibliometric indicators to monitor this process, Hrčak has never contained bibliometric data. Similarly to SciELO (Packer 87-95) and 
Redalyc (Aguado López and Becerril-Garcia 122-34), the development of bibliometric indicators and other (alternative) metrics adjusted to local needs is highly relevant for SCIndeks. As citation indexes, SciELO and SCIndeks pay great attention to the internal and external linking of references and all other aspects of metadata relevant for citation tracking. On the other hand, AJOL evaluated journals based on the transparency of their editorial policies..$^{10}$ In brief, these local/regional platforms, including SCIndeks, respond to clearly identified needs. The fact that they are constantly growing in terms of content size, the number of journals and technical versatility shows that the needs persist and that target groups - both publishers and the readership - are stable.

On the other hand, the comparison reveals a whole range of hybrid solutions with varying degrees of receptiveness to global developments. For example, the focus on $\mathrm{OA}$ was not necessarily planned in an early stage of development. All analyzed platforms, except Redalyc, were initially bibliographic databases where a significant number of articles were not available as full text. Despite the apparent convergence towards greater openness, AJOL still covers subscription-based journals. SciELO has recently introduced support for preprints (Packer, 'The Road to Preprints (Part 2)'). Selection criteria are also changing. SCIndeks and SciELO have changed their acceptance criteria to include full-text articles only. SciELO also requires journals to be indexed in DOAJ, publish under the Creative Commons Attribution License (CC BY) and have the full text in the XML format. ${ }^{11}$ This last requirement is also put forward by Redalyc, which accepts only no-fee journals published by non-profit organizations which signed the San Francisco Declaration on Research Assessment (DORA) (Becerril-García and Aguado- López). These developments are determined by local contexts and policies, and they reveal that national/regional platforms not only translate global trends into local needs, but they are also ready to take leadership in innovation.

OJS, as a constantly developing free and open-source solution (OJS), has certainly played an important role in the development of online publishing worldwide, and especially in developing countries. The presented platforms show a whole range of integrations between OJS and the already existing broader systems of services and tools. In this context, AJOL stands out as a platform fully powered by OJS.

The aforementioned platforms play an important role in the preservation of multilingualism in scholarly publishing, although the internationalization of scholarship inevitably leads to the growth of the English-language content (Packer, 'The Adoption of English among SciELO Brazil Journals Has Been Increasing'). The same trend may be observed in SCIndeks, which fully supports publication in various languages: the share of the English-language full-text content has constantly increased to reach $59.82 \%$ in 2019 . However, the situation is considerably different in humanities, where about $85 \%$ of articles are published in Serbian.

34 All analyzed platforms started as fully or partly publicly funded projects. The example of SCIndeks indicates that unexpected shifts in the policies of public funders are not impossible, regardless of the platform's size, vitality and efficiency, but that there is a life beyond public funding. In these terms, the response of SCIndeks to a dramatically changed situation may be instructive for the platforms, especially national, that (still) rely on public financing. 


\section{Conclusion}

CEON/CEES has managed to establish a sustainable publishing platform by downscaling and adapting global models and good practices to a national level. It offers services that most journals could not provide due to limited resources and expertise. The provided services, tools and technical support enable editorial staff to focus on the editorial process and content. Affordable service packages, at a fee by far lower than that offered by international publishers, enable academic institutions and learned societies to retain full control of the editorial process and to keep on publishing, if they wish, in the local language or any other language relevant for their area of research. At the same time, the platform ensures visibility, interoperability with international infrastructures, and compliance with the leading international initiatives in $\mathrm{OA}$ publishing. The sustainability of the underlying business model rests in the fact that the platform efficiently meets the needs of local journal publishers by providing costeffective services.

The shift to a new business model relied on a solid strategy as much as it was a result of efficient crisis management. The cessation of public funding was neither expected nor duly announced. The example of SCIndeks suggests that multifunctional platforms, where it is possible to redefine the balance between functions, have greater chances of survival when faced with funding disruptions.

In this study, we did not have the possibility of using ordinary measures of economic sustainability, nor doctrinal conditions for applying statistical instruments for testing the significance of observed trends. However, even though it might be relatively weak, descriptive methodology applied has been sufficient to demonstrate that a non-profit organisation with a business model based on "self-financing", and an extremely modest budget, can remain $\mathrm{OA}$, be sustainable, and even economically superior to the publicly funded model of journal publishing, at least in some socio-political and academic environments.

\section{BIBLIOGRAPHY}

'A New SCIndeks Functionality: Policy and Licensing Support Service'. CEON/CEES - Centre for Evaluation in Education and Science, 2 July 2017, www.ceon.rs/index.php? option=com_content\&view=article\&id=568\&cat\%20id=172\&Itemid=579\&lang=en .

Aguado López, Eduardo, and Arianna Becerril-Garcia. 'Redalyc. A Platform of Visibility for the Scientific Production Published in Open Access Ibero- American Journals'. Open Access Indicators and Scholarly Communications in Latin America, edited by Juan Pablo Alperin et al., CLACSO; UNESCO, 2014, pp. 97-142. OpenWorldCat, biblioteca.clacso.edu.ar/clacso/se/20140917054406/ OpenAccess.pdf.

Aguado-López, Eduardo, and Arianna Becerril-Garcia. 'AmeliCA before Plan S - The Latin American Initiative to Develop a Cooperative, Non-Commercial, Academic Led, System of 
Scholarly Communication'. Impact of Social Sciences, 8 Aug. 2019, blogs.lse.ac.uk/ impactofsocialsciences/2019/08/08/amelica-before-plan-s-the-latin-american-initiative-todevelop-a-cooperative-non-commercial- academic-led-system-of-scholarly-communication/.

Alperin, Juan Pablo. 'Open Access Indicators. Assessing Growth and Use of Open Access Resources from Developing Regions. The Case of Latin America'. Open Access Indicators and Scholarly Communications in Latin America, edited by Juan Pablo Alperin et al., CLACSO; UNESCO, 2014, pp. 15-78. Open WorldCat, biblioteca.clacso.edu.ar/clacso/se/20140917054406/OpenAccess.pdf.

Austin, Claire C., et al. 'Key Components of Data Publishing: Using Current Best Practices to Develop a Reference Model for Data Publishing'. International Journal on Digital Libraries, vol. 18, no. 2, June 2017, pp. 77-92. Springer Link, doi:10.1007/s00799-016-0178-2.

'Award and Acknowledgments for the Reviewers of SCIndeks Assistant Journals Established'. CEON/CEES - Centre for Evaluation in Education and Science, 13 Mar. 2019, www.ceon.rs/index.php? option=com_content\&view=article\&id=615\&cat\%20id=170\&Itemid=574\&lang=en.

Becerril-García, Arianna \& Eduardo Aguado-López. 'The End of a Centralized Open Access Project and the Beginning of a Community-Based Sustainable Infrastructure for Latin America : Redalyc.Org after Fifteen Years'. Connecting the Knowledge Commons - From Projects to Sustainable Infrastructure: The 22nd International Conference on Electronic Publishing - Revised Selected Papers, edited by Leslie Chan and Pierre Mounier, OpenEdition Press, 2019, pp. 41-55. OpenEdition Books, books.openedition.org/oep/9003.

Cetto, Ana María, and Jose Alonso-Gamboa. 'Scientific Periodicals in Latin America and the Caribbean: A Global Perspective’. Interciencia, vol. 23, 1998, pp. 84- 93.

Crawford, Walt. Gold Open Access by Country 2013-2018: Supplement ToGold OpenAccess 2013-2018: Articles Injournals (GOA4). Cites \& Insights Books, 2019.

'DoiSerbia'. Open Access Success Stories, www.oastories.org/2011/09/serbia- repository-doiserbia/ \#more-16.

Kosanović, Biljana, and Pero Šipka. 'SocioFakt - Jugoslovenska Baza Za Društvene Činjeničke Nauk'. Merenje u Psihologiji 2, IKSI; Centar za primenjenu psihologiju, 1996, pp. 85-95, www.ceon.rs/ images/pdf/sociofakt_jugoslovenska_baza_za_drustvene_ci\%20njenicke_nauke.pdf.

Marchitelli, Andrea, et al. 'Improvement of Editorial Quality of Journals Indexed in DOAJ: A Data Analysis'. JLIS.It, vol. 8, no. 1, Jan. 2017, pp. 1-21. www.jlis.it, doi:10.4403/jlis.it-12052.

Marx, Werner, and Lutz Bornmann. 'Journal Impact Factor: “The Poor Man's Citation Analysis” and Alternative Approaches : Journal: European Science Editing'. European Science Editing, vol. 39, no. 3, 2013, pp. 62-63, europeanscienceediting.eu/articles/journal-impact-factor-the-poor-manscitation-analysis-and-alternative-approaches/.

Meneghini, Rogerio, and Abel L. Packer. 'Is There Science beyond English?' EMBO Reports, vol. 8, no. 2, John Wiley \& Sons, Ltd, Feb. 2007, pp. 112-16. embopress.org (Atypon), doi:10.1038/sj.embor. 7400906.

Packer, Abel. 'The Adoption of English among SciELO Brazil Journals Has Been Increasing'. SciELO in Perspective, 2016, blog.scielo.org/en/2016/05/10/the-adoption-of-english-among-scielo- braziljournals-has-been-increasing.

Packer, Abel. 'The Metrics Used in the Development of the SciELO Network Model'. Open Access Indicators and Scholarly Communications in Latin America, edited by Juan Pablo Alperin et al., CLACSO; UNESCO, 2014, pp. 81-96. OpenWorldCat, biblioteca.clacso.edu.ar/clacso/se/ 20140917054406/OpenAccess.pdf. 
Packer, Abel. ‘The Road to Preprints (Part 2): SciELO’s Preprint Server | Public Knowledge Project'. PKP-Public Knowledge Project, 3 Mar. 2020, pkp.sfu.ca/2020/03/03/the-road-to-preprintspart-2-scielos-preprint- server/.

Popovic, Aleksandra, et al. 'The Role of National Citation Index in the Evaluation of National Science'. 3rd International Conference The Future of Information Sciences (INFuture) INFuture2011: "Information Sciences and e-Society, Department of Information Sciences. Faculty of Humanities and Social Sciences, University of Zagreb, 2011, pp. 43-49, infoz.ffzg.hr/bookstore/files/ INFuture2011.pdf.

'Principles and Implementation'. Plan S: Making Full and Immediate Open Access a Reality, 2018, www.coalition-s.org/addendum-to-the-coalition-s-guidance-on-the-implementation-of-plan-s/ principles-and-implementation/.

Rosenberg, Diana. 'African Journals Online: Improving Awareness and Access'. Learned Publishing, vol. 15, no. 1, 2002, pp. 51-57. Wiley Online Library, doi:10.1087/095315102753303689.

Ross-Hellauer, Tony. 'What Is Open Peer Review? A Systematic Review'. F1000Research, vol. 6, Aug. 2017. PubMed Central, doi:10.12688/f1000research.11369.2.

'SCIndeks Changed Its Shape, Scope, and Funding Model - CEON/CEES Announcement'. CEON/CEES - Centre for Evaluation in Education and Science, 15 Mar. 2015, www.ceon.rs/index.php? option=com_content\&view=article\&id=485\&catid=171\&Itemid=588\&lang=en.

Ševkušić, Milica, et al. Open Access Journals in Serbia: Policies and Practices. National Library of Serbia, 2017.

Šipka, Pero. 'Bibliometric Quality of Serbian Journals 2002-2011: More Than Just a Dress for Success'. Journal Publishing in Developing, Transition and Emerging Countries, Centre for Evaluation in Education and Science, 2013, pp. 161-65. DOI.org (Crossref), doi:10.5937/BIOAC-110.

Šipka, Pero. Supporting SCIndeks Improvements through Alternative Funding Mechanism: CEON/CEES Project Execution Final Report. Centre for Evaluation in Education and Science, 6 Mar. 2017, p. 4, www.ceon.rs/pdf/Alternative_Funding_Mechanism.pdf.

Šipka, Pero. 'The Serbian Citation Index: Context and Content'. Proceedings of ISSI 2005 - the 10th International Conference of the Information Society for Scientometrics and Informetrics, Stockholm, Sweden, July 24-28, 2005, vol. 2, SSI and Karolinska University Press, 2005, pp. 710-11. Google Scholar, www.ceon.org.rs/pdf/Sipka_SCIndeks_poster.pdf.

Šipka, Pero, and Biljana Kosanović. 'The National Citation Index as a Platform to Achieve Interoperability of a National Journals Repository'. Third International Conference on Open Repositories 2008, 2008. pubs.or08.ecs.soton.ac.uk, pubs.or08.ecs.soton.ac.uk/60/.

Solomon, David, et al. 'Converting Scholarly Journals to Open Access: A Review of Approaches and Experiences'. Copyright, Fair Use, Scholarly Communication, Etc., Jan. 2016, digitalcommons.unl.edu/ scholcom/27.

Stojanovski, Jadranka, et al. 'The Croatian National Open Access Journal Platform'. Learned Publishing, vol. 22, no. 4, 2009, pp. 263-73. Wiley Online Library, doi:10.1087/20090402.

Van Leeuwen, Thed N., et al. 'Language Biases in the Coverage of the Science Citation Index and Its Consequences for International Comparisons of National Research Performance'. Scientometrics, vol. 51, no. 1, Apr. 2001, pp. 335-46. Springer Link, doi:10.1023/A:1010549719484. 


\section{NOTES}

1. These include: doiSerbia (http://www.doiserbia.nb.rs/; 56 journals by public research organizations and learned societies, no new journals added since 2011), in-house publicly funded platform maintained by the National Library of Serbia, established in 2005 with the idea of enabling DOI assignment to articles in selected journals ('DoiSerbia'); Doi Fil (http:// doi.fil.bg.ac.rs; 28 journals by academic and commercial publishers), in-house platform maintained by the Faculty of Philology, University of Belgrade, where DOIs are assigned to journals and edited volumes for a fee; the OJS-based platforms hosting multiple journals published by the University of Niš (http://casopisi.junis.ni.ac.rs; 18 journals) and the Faculty of Philosophy, University of Novi Sad (http://epub.ff.uns.ac.rs; 12 journals). Only one among these platforms supports OAI-PMH and provides the search functionality.

2. JBR was not publicly available. Access was limited to the academic community of Serbia.

3. Only nine journals hosted by SCIndeks charge some fees (either article processing charges or submission charges).

4. The motives of the Ministry to withhold support to SCIndeks and the behaviour of its top officials in this strikingly odd decision deserve separate study, which is in preparation.

5. SCindeks Asistent is powered by OJS. The publishing process is supported by screening for plagiarism (iThenticate) and a number of in-house developed tools enabling keyword enrichment, normalization and formatting of cited references, matching in-text citations and cited references, discovering retracted articles or articles from disputable journals among cited references, assessment of peer-reviewers by manuscript authors, etc.

6. CEON/CEES does not interfere with publishers' editorial procedures. However, it reserves the right to suspend journals from SCIndeks due to unethical or disputable practices (e.g. failure to respond to plagiarism and other forms of misconduct, non-compliance with the proclaimed journal policies, etc.).

7. Cf.http://jbr.ceon.rs/help/help.html

8. CEON/CEES personnel is made of 5 permanently employed staff, 5-8 part-timers, and 3 executives as volunteers.

9. The Journals Online (JOLs) project has been implemented by the International Network for the Availability of Scientific Publications (INASP), Oxford, United Kingdom. Similar platforms are established in Sri Lanka, Bangladesh, Mongolia, Central America, Philippines, Nepal and Vietnam. 10. JPPS framework: badges indicating the transparency and quality of editorial procedures: www.journalquality.info/en.

11. Cf. https://wp.scielo.org/wp-content/uploads/Criterios-Rede-SciELO-en.pdf. Specific criteria may apply for national collections.

\section{ABSTRACTS}

The paper presents an in-depth analysis of the innovative business model underlying the Serbian Citation Index (SCIndeks), as a local Open Access publishing platform in Serbia. It explains the role of the platform in the local publishing ecosystem and its international relevance in terms of interoperability, multilingualism, promotion of local research, development of good publishing practice and evaluation indicators, demonstrating that the only way to ensure a sustainable future of local journals is devising publishing models adjusted to the local context and needs 
relying on extensive research and receptiveness for global trends. The paper focuses on the period after 2015, when the business model was changed from a publicly funded project to a platform maintained in a partnership between a web publisher and journal owners, marked by extensive guidance and strict quality control. The results of the comparisons between the old and the new model and between SCIndeks and similar platforms indicate that such a model may be sustainable and even superior to the publicly funded model of journal publishing, at least in some socio-political and academic environments.

\section{INDEX}

Keywords: national publishing platforms, no-fee open access, interoperability, business models, sustainability

\section{AUTHORS}

\section{MILICA ŠEVKUŠIĆ}

Institute of Technical Sciences of SASA and Centre for Evaluation in Education and Science (CEON/CEES), Belgrade, Serbia

\section{BILJANA KOSANOVIĆ}

University of Belgrade Computer Centre and Centre for Evaluation in Education and Science (CEON/CEES), Belgrade, Serbia

\section{PERO ŠIPKA}

Centre for Evaluation in Education and Science (CEON/CEES), Belgrade, Serbia ceon@ceon.rs

(corresponding author) 